\title{
Differences in Cognition Regarding "Difficult-to-Raise" Preschool Children between Parents and a Teacher in the Philippines
}

\author{
Yaho Yamamoto ${ }^{1,2, *}$, Hiroya Matsuo ${ }^{1}$ \\ ${ }^{1}$ Kobe University Graduate School of Health Science, Tomogaoka 10-2-7, Suma-ku, Kobe, Hyogo, 654-0142, Japan \\ ${ }^{2}$ Child Welfare Facility for Children with Disabilities "Ippo Ippo", Specified Nonprofit Corporation Reha-Care Kobe, \\ Tamatsu-cho-tanaka 597-1, Nishi-ku, Kobe, Hyogo, 651-2147, Japan
}

Received January 29, 2020; Revised March 3, 2020; Accepted March 19, 2020

Copyright $\bigcirc 2020$ by authors, all rights reserved. Authors agree that this article remains permanently open access under the terms of the Creative Commons Attribution License 4.0 International License

\begin{abstract}
The cognition of parents and teachers regarding "difficult-to-raise" children are important in the development of children. Differences between parents and teachers in this respect may have a negative impact on children's development. The aim of this study is to examine the current status of the cognition of parents and teachers on child-raising anxiety and compare the results between parents and a teacher. Parents and a teacher of children attending a preschool learning center participated in the study. A questionnaire survey was conducted among parents concerning their child-raising anxieties. The percentages of children regarding whom the parents felt child-raising anxiety ranged from $3.3 \%$ to $13.3 \%$, while the corresponding percentages for the teacher ranged from $0 \%$ to $7.5 \%$. Three different factors were related to child-raising anxiety in the parents: the Kaup index, whether or not the child was the first child, and the place of delivery. In conclusion, there were some differences in the child-raising anxieties. The Kaup index, whether the child is the first child or not, and the place of delivery might affect the cognition of parents regarding whether they felt the child was difficult to raise.
\end{abstract}

Keywords Difficult-to-Raise Children, Child-raising Anxieties, Parent, Teacher

\section{Introduction}

The factors that produce "difficult-to-raise children" tend to appear when the children experience group life, such as at preschool. These include disposition, natural temperament, and whether or not the child has any mild developmental disorders [1]. Parents and teachers may face problems regarding the difficulty-to-raise children regardless of the causes. Childcare by parents and teachers may strongly influence the development of children for better or for worse. Thus, the cognition of parents and teachers regarding difficult-to-raise preschool children is important for the development of children.

Meanwhile, it has been reported that the total fertility rate of the Philippines is 3.0 [2], and the percentage of infants with a low birth weight is $20 \%$ [3]. These indicators are higher in the Philippines than in other Southeast Asian countries. It is well known that low-birth-weight infants are more likely to suffer health problems such as developmental disorders. Additionally, there is no support system such as checkups for the early detection of difficult-to-raise children in the Philippines [4]. Actually, we have demonstrated that parents in deprived areas of the Philippines felt various child-raising anxieties regarding their children's eyesight, hearing, speech, and growth through medical checkups that we had originally performed [5]. We defined child-raising anxiety as a state that some problems in child-raising such as anxiety, trouble, fatigue, and irritation have not been resolved and built up in the article. However, there have been no reports demonstrating differences between parents and teachers in the cognition of difficulty-to-raise children in the Philippines. It is possible that the differences between parents and teachers in this respect may have a negative impact on child development.

Therefore, we examined the current status of the cognition of parents and teachers in terms of child-raising anxiety regarding such matters as eyesight, hearing, speech, growth and difficult-to-raise children in a preschool learning center in Malabon city in the Philippines, and compared the results between the parents and the teachers. 


\section{Materials and Methods}

\subsection{Subjects}

In total, 120 parents of children who belonged to the Kinder class (mean age $4.8 \pm 0.5$ years old) and a female teacher of the Kinder class who was qualified under the national examination and who had 22 years of teaching experience were enrolled in the study.

Medical checkups were carried out at the Abakadang Kayumanggi Community Development Foundation Preschool Learning Center (AKCDF) near a deprived area called East River Side, in Malabon city, the Philippines.

This research was approved by the Ethics Committee of Kobe University Graduate School of Health Sciences (Approval no. 689). A representative of AKCDF explained the details of the medical checkups to the parents in advance, and the parents who gave their consent participated in this study. Written informed consents details were obtained from the AKCDF representative and all the parents and the teachers who participated in the medical checkups.

\subsection{Survey Contents}

\subsubsection{Reception and Questionnaire Answered by Parents}

AKCDF staff were in charge of the reception. A questionnaire survey was undertaken. The questionnaire comprised the characteristics of the parents (sex, student contribution level (SCL), possession of maternity record book, age at pregnancy, child's birth weight, method of delivery, place of delivery); the characteristics of the children (name, sex, age, whether or not the first child); child-raising anxieties (eyesight, hearing, speech, growth, difficult-to-raise child); issues of difficulty of raising (hyperactivity, inattention, frequent panic attacks, inability to wait for instructions, extremely unbalanced diet, violence, no concerns regarding character, others). For its preschool program, AKCDF categorized SCL into five levels $(1,2 \mathrm{~A}, 2 \mathrm{~B}, 3 \mathrm{~A}$, and $3 \mathrm{~B})$ depending on the family's income opportunities and ownership of property.

SCL 1 and SCL 2A were defined as one or both parents being professionals and regularly employed, with a combined gross income of above 8,000 Philippine pesos; SCL 1 included other sources of income or support, whereas SCL 2A did not include other sources of income. SCL $2 \mathrm{~B}$ was defined as one or both parents being ordinary workers and regularly employed, with low income and irregular work. SCL 3A and SCL 3B were defined as one or both parents being employed with unstable income, with SCL 3B including a family crisis (e.g., sickness, abandonment by spouse, or no regular source of income).

\subsubsection{Questionnaire Answered by the Teacher}

The questionnaire comprised the characteristics of the teacher (name, sex, age, qualification, years of experience as a teacher); child-raising anxieties (eyesight, hearing, speech, growth, difficult-to-raise child); issues of difficulty of raising (hyperactivity, inattention, frequent panic attacks, inability to wait for instructions, extremely unbalanced diet, violence, no concern about character, others). We also conducted a direct interview with the teacher.

\subsubsection{Statistical Analyses}

All the statistical analyses were performed with EZR (produced by Saitama Medical Center, Jichi Medical University), which is a graphical user interface for R (The R Foundation for Statistical Computing). More precisely, it is a modified version of R Commander designed to add statistical functions frequently used in bio statistics (Kanda, 2013). Statistical significance was determined using one-way ANOVA and the Fisher test, and values of $\mathrm{p}<0.05$ were considered significant.

\section{Results}

\subsection{Characteristics of Subjects}

Table 1. Characteristics of Subjects

\begin{tabular}{|c|c|c|c|}
\hline \multicolumn{4}{|l|}{ Parents $(n=120)$} \\
\hline \multirow{2}{*}{$\operatorname{Sex}(n)(\%)$} & Male & 11 & 9.2 \\
\hline & Female & 109 & 90.8 \\
\hline \multirow{5}{*}{$\begin{array}{l}\text { Economic Situation of Parents } \\
\text { SCL (n) }(\%)\end{array}$} & 1 & 4 & 3.3 \\
\hline & $2 \mathrm{~A}$ & 18 & 15.0 \\
\hline & 2B & 83 & 69.2 \\
\hline & $3 \mathrm{~A}$ & 12 & 10.0 \\
\hline & $3 \mathrm{~B}$ & 3 & 2.5 \\
\hline \multirow{3}{*}{$\begin{array}{l}\text { Have Maternity Record Book (n) } \\
(\%)\end{array}$} & Yes & 92 & 76.7 \\
\hline & No & 25 & 20.8 \\
\hline & Not sure & 3 & 2.5 \\
\hline \multicolumn{4}{|l|}{ Students $(n=120)$} \\
\hline \multirow{2}{*}{$\operatorname{Sex}(n)(\%)$} & Male & 56 & 46.7 \\
\hline & Female & 64 & 53.3 \\
\hline \multicolumn{2}{|l|}{ Mean Age (n) (y) (Mean \pm SD) } & 120 & $4.8 \pm 0.5$ \\
\hline \multirow[t]{2}{*}{ First child (n) (\%) } & $\begin{array}{l}\text { First } \\
\text { child }\end{array}$ & 61 & 50.8 \\
\hline & Others & 59 & 49.2 \\
\hline \multicolumn{4}{|l|}{ Teacher $(\mathrm{n}=1)$} \\
\hline Sex & \multicolumn{3}{|l|}{ Female } \\
\hline Age & \multicolumn{3}{|l|}{50} \\
\hline Qualification & \multicolumn{3}{|c|}{ Qualified teacher } \\
\hline Years of Experience & \multicolumn{3}{|l|}{22 years } \\
\hline
\end{tabular}

Table 1 shows the characteristics of the subjects. The percentage breakdown of the SCLs, which indicate the economic situations of the parents, were 3.3\% (SCL 1), 
$15.1 \%$ (SCL 2A), $69.2 \%$ (SCL 2B), 10.0\% (SCL 3A), and $2.5 \%$ (SCL 3B). The percentage of children for whom the parents possessed a maternity record book was $76.7 \%$. In total, 120 children (mean age $4.8 \pm 0.5$ years old; 56 boys and 64 girls) who belonged to the Kinder class, and their parents, were enrolled in the study.

\subsection{The cognition of Parents and the Teacher regarding Child-Raising Anxiety}

Table 2. Cognition of Parents and Teacher on Child-raising

\begin{tabular}{|c|c|c|c|c|c|}
\hline \multirow{2}{*}{\multicolumn{2}{|c|}{ Child-raising anxiety }} & \multicolumn{4}{|c|}{ Students $(n=120)$} \\
\hline & & \multicolumn{2}{|c|}{ Parents (n) (\%) } & \multicolumn{2}{|c|}{ Teacher $(\mathrm{n})(\%)$} \\
\hline \multicolumn{2}{|c|}{ Eyesight } & 4 & 3.3 & 1 & 0.8 \\
\hline \multicolumn{2}{|c|}{ Hearing } & 6 & 5.0 & 0 & 0.0 \\
\hline \multicolumn{2}{|c|}{ Speech } & 6 & 5.0 & 1 & 0.8 \\
\hline \multicolumn{2}{|c|}{ Growth } & 6 & 5.0 & 9 & 7.5 \\
\hline \multicolumn{2}{|c|}{ Difficult to raise } & 16 & 13.3 & 9 & 7.5 \\
\hline \multirow{8}{*}{$\begin{array}{l}\text { Difficult } \\
\text { to raise }\end{array}$} & Hyperactivity & 9 & 7.5 & 4 & 3.3 \\
\hline & Inattention & 9 & 7.5 & 2 & 1.7 \\
\hline & $\begin{array}{c}\text { Inability to } \\
\text { wait for } \\
\text { orders }\end{array}$ & 2 & 1.7 & 0 & 0.0 \\
\hline & $\begin{array}{c}\text { Frequent } \\
\text { panic attacks }\end{array}$ & 1 & 0.8 & 1 & 0.8 \\
\hline & $\begin{array}{c}\text { Extremely } \\
\text { unbalanced } \\
\text { diet }\end{array}$ & 8 & 6.7 & 3 & 2.5 \\
\hline & $\begin{array}{c}\text { No concern } \\
\text { regarding } \\
\text { character }\end{array}$ & 0 & 0.0 & 0 & 0.0 \\
\hline & Violence & 0 & 0.0 & 3 & 2.5 \\
\hline & Other & 0 & 0.0 & 4 & 3.3 \\
\hline
\end{tabular}

Table 2 shows the results of the cognition of the parents and the teacher regarding child-raising anxiety. The percentages of children for whom the parents felt child-raising anxiety regarding specific issues were $3.3 \%$ for eyesight, $5.0 \%$ for hearing, $5.0 \%$ for speech, $5.0 \%$ for growth, and $13.3 \%$ for difficult-to-raise children. The percentages of children regarding whom the teacher felt child-raising anxiety were $0.8 \%$ for eyesight, $0 \%$ for hearing, $0.8 \%$ for speech, $7.5 \%$ for growth, and $7.5 \%$ difficult-to-raise children. The percentages of children regarding whom the parents felt anxiety tended to be higher than the percentages of children for whom the teacher felt anxiety, and there were some differences in the details of the child-raising anxieties between the parents and the teacher. The percentages of children whom the parents felt to be difficult-to-raise (in terms of hyperactivity, inattention, or extremely unbalanced diet) were higher than the corresponding percentages for the teacher. The percentages of children whom the teacher who felt to be difficult-to-raise in terms of violence were higher than the corresponding percentages for the parents.

\subsection{Concurrence of the Cognition of Child- Raising Anxiety between the Parents and the Teacher}

Table 3 shows the concurrence of child-raising anxiety between the parents and the teacher. The percentage of children regarding whom both the parents and the teacher felt anxiety was $16.0 \%$. The percentage of children regarding whom the teacher felt anxiety but the parents did not was $8.4 \%$. The percentage of the children regarding whom the teacher did not feel anxiety but the parents did was $84.0 \%$. The percentage of children regarding whom neither the parents nor the teacher felt anxiety was $91.6 \%$.

Table 3. Concurrence of the Cognition on Child-raising Anxiety

\begin{tabular}{|c|c|c|c|c|}
\hline $\begin{array}{c}\text { Cognition on Child-raising } \\
\text { Anxiety }\end{array}$ & \multicolumn{2}{|c|}{$\begin{array}{c}\text { Parents }(+) \\
(\mathrm{n}=25) \\
(\mathrm{n})\end{array}$} & \multicolumn{2}{|c|}{$\begin{array}{c}\text { Parents }(-) \\
(\mathrm{n}=95) \\
(\mathrm{n})(\%)\end{array}$} \\
\hline Teacher $(+)$ & 4 & 16.0 & 8 & 8.4 \\
\hline Teacher (-) & 21 & 84.0 & 87 & 91.6 \\
\hline
\end{tabular}

\subsection{Factors Related to Child-Raising Anxiety of the Parents}

Table 4 shows factors related to child-raising anxiety in the parents. The percentage of children regarding whom the parents felt child-raising anxiety when the child was underweight or obese was higher than in the case of other children $(\mathrm{p}=0.07)$. The percentage of children regarding whom the parents felt child-raising anxiety when the child was the first child was higher than in the case of other children $(p=0.1)$. The percentage of children regarding whom the parents felt child-raising when the child was born by a home delivery was higher than when the child was born in a hospital, barangay health center, or midwifery home $(\mathrm{p}=0.07)$. 
Differences in Cognition regarding "Difficult-to-Raise" Preschool Children between Parents and a Teacher in the Philippines

Table 4. Factors Related to Child-raising Anxiety

\begin{tabular}{|c|c|c|c|c|c|}
\hline \multirow{3}{*}{\multicolumn{2}{|c|}{ Factors Related to Child-raising Anxiety }} & \multicolumn{4}{|c|}{ Students $(n=120)$} \\
\hline & & \multicolumn{2}{|c|}{ Anxiety + (n) (\%) } & \multicolumn{2}{|c|}{ Anxiety - (n) (\%) } \\
\hline & & 26 & 21.7 & 94 & 78.3 \\
\hline \multirow{3}{*}{$\operatorname{Sex}(n)(\%)$} & Male & 14 & 53.8 & 44 & 46.8 \\
\hline & Female & 12 & 46.2 & 52 & 55.3 \\
\hline & p-value & \multicolumn{4}{|c|}{$\mathrm{NS}(0.51)$} \\
\hline \multirow{3}{*}{$\mathrm{SCL}(\mathrm{n})(\%)$} & Above 2B & 24 & 92.3 & 81 & 86.2 \\
\hline & Below 3A & 2 & 7.7 & 13 & 13.8 \\
\hline & p-value & \multicolumn{4}{|c|}{$\mathrm{NS}(0.52)$} \\
\hline \multirow{4}{*}{$\begin{array}{l}\text { Kaup index } \\
\text { (n) }(\%)\end{array}$} & Underweight & 2 & 7.7 & 2 & 2.1 \\
\hline & Obese & 2 & 7.7 & 2 & 2.1 \\
\hline & Other & 22 & 90 & 90 & 95.7 \\
\hline & p-value & \multicolumn{4}{|c|}{ NS（0.07） } \\
\hline \multirow{3}{*}{$\begin{array}{l}\text { First child } \\
\text { (n) }(\%)\end{array}$} & First child & 14 & 53.8 & 41 & 43.6 \\
\hline & Other & 8 & 30.8 & 48 & 51.1 \\
\hline & $\mathrm{p}$-value & \multicolumn{4}{|c|}{ NS (0.14) } \\
\hline \multirow{5}{*}{ Gestational age $(n)(\%)$} & Premature delivery & 0 & 0.0 & 1 & 1.1 \\
\hline & Normal & 24 & 92.3 & 52 & 55.3 \\
\hline & Over-term delivery & 0 & 0.0 & 2 & 2.1 \\
\hline & Unknown & 2 & 7.7 & 39 & 41.5 \\
\hline & $\mathrm{p}$-value & \multicolumn{4}{|c|}{ NS（0.56） } \\
\hline \multirow{5}{*}{ Mode of delivery $(\mathrm{n})(\%)$} & Normal & 22 & 84.6 & 71 & 75.5 \\
\hline & Cesarean section & 1 & 3.8 & 6 & 6.4 \\
\hline & Forceps delivery & 0 & 0.0 & 6 & 6.4 \\
\hline & Unknown & 3 & 11.5 & 11 & 11.7 \\
\hline & p-value & \multicolumn{4}{|c|}{ NS (0.29) } \\
\hline \multirow{6}{*}{ Place of delivery (n) $(\%)$} & Hospital & 16 & 61.5 & 65 & 69.1 \\
\hline & Barangay Health Center & 2 & 7.7 & 6 & 6.4 \\
\hline & Midwifery home & 4 & 15.4 & 15 & 16.0 \\
\hline & House & 4 & 15.4 & 4 & 4.3 \\
\hline & Unknown & 0 & 0.0 & 3 & 3.2 \\
\hline & $\mathrm{p}$-value & \multicolumn{4}{|c|}{ NS（0.07） } \\
\hline \multirow{4}{*}{$\begin{array}{c}\text { Maternity record book } \\
\text { (n) }(\%)\end{array}$} & Have & 20 & 76.9 & 72 & 76.6 \\
\hline & Do not have & 6 & 23.1 & 19 & 20.2 \\
\hline & Unknown & 0 & 0.0 & 3 & 3.2 \\
\hline & p-value & \multicolumn{4}{|c|}{ NS（0.79） } \\
\hline \multirow{3}{*}{ Birthweight } & (n) $(\mathrm{g})($ Mean \pm SD $)$ & 9 & $3264.4 \pm 595.9$ & 38 & $3009.7 \pm 566.2$ \\
\hline & Unknown (n) & & 10 & & 63 \\
\hline & p-value & \multicolumn{4}{|c|}{ NS（0.24） } \\
\hline
\end{tabular}




\section{Discussion}

This is the first time a study has been conducted to demonstrate that there are differences in the cognition of child-raising anxiety between parents and the children's teacher. The percentages of children regarding whom the parents felt anxiety tended to be higher than the corresponding percentages for the teacher, and there were some differences in the details of the child-raising anxieties between the parents and the teacher. The percentages of children whom the parents felt to be difficult-to-raise (in terms of hyperactivity, inattention, or extremely unbalanced diet) were higher than the corresponding percentages for the teacher. The percentages of children whom the teacher who felt difficult-to-raise in terms of violence were higher than the corresponding percentages for the parents. It was suggested that the Kaup index, whether or not the child was the first child, and the place of delivery might affect the cognition of parents regarding whether or not they felt their child was difficult to raise.

It was demonstrated in this study that the parents and the teacher felt various child-raising anxieties, including regarding the child being difficult to raise. This suggests that the parents and teachers face problems regarding the difficult-to-raise children in the Philippines. The results of the cognition of child-raising anxiety between the parents and the teacher conflicted. The percentages of children regarding whom the parents felt child-raising anxiety tended to be higher than the corresponding percentages for the teacher. According to the teachers of AKCDF, they did not recognize that the parents felt various child-rearing anxieties, including regarding difficult-to-raise children. It is possible that the parents felt excessive anxieties about child-raising and confused inattention in their children with low vision, hearing loss or speech delay. It is essential that teachers recognize the cognition of the parents and provide consultation to parents who have child-raising anxiety. It is also necessary to provide educational assistance to teachers.

Interestingly, some parents felt child-raising anxiety regarding an extremely unbalanced diet, whereas the teacher did not have child-raising anxiety regarding this issue. One possible explanation is that teachers do not have a chance to be aware of extremely unbalanced diets because the school does not provide meals but simply snacks for the children. Meanwhile, the teacher felt some children were difficult to raise in terms of the issue of violence, whereas no parents felt so. The results thus conflicted. According to the teacher at AKCDF, abused children exercise violence at preschool. It is known that being considered a difficult-to-raise child is one of the risk factors of child abuse [6]. It is important that both parents and teachers recognize the differences in their feelings of child-raising anxiety. These differences may result in secondary damage against children considered to be difficult to raise. Difficult-to-raise children have fewer opportunities to undergo medical and educational rehabilitation by health professionals compared to children with physical handicaps [7].

Three different factors were found to be related to child-raising anxiety among parents. One was physical growth, with parents suggesting that underweight and obese children are more likely to have health problems. As for the association between child-raising anxiety of the parents and the child being the first child, the parents may feel excessive anxieties about child-raising due to lack of skills. A previous study revealed that lack of skill in child-raising was a factor causing some parents to feel their child was difficult to raise [8]. As for place of delivery, there is a possible explanation for this result. Lack of knowledge of proper medical treatment for delivery may contribute to the feeling of child-raising anxiety. We also investigated the relationship between possession of a maternity book, place of delivery, and SCL through a questionnaire. $76.7 \%$ of parents had a maternity record book and $20.8 \%$ of parents did not have one. As for the place of delivery, the ratio of parents who did not have a maternity record book who had a home delivery was higher. As for SCL, the ratio of children in $3 \mathrm{~A}$ and below who had a maternity record book tended to be lower than those in $2 \mathrm{~B}$ and above. According to these findings, we inferred that poverty is expected to correlate with home delivery and not having a maternity record book. The Ministry of Health and Welfare of the Philippines introduced a maternity record book called the "Mother and Child Book" to improve the level of maternal and child health in 2005 [9], although these results led us to speculate that possession of the maternity record book has not yet become widespread among poor families in deprived areas of the Philippines. Encouraging use of the maternity record book would be an effective means of giving parents correct knowledge of child-raising.

Additional studies including more participants in various parts of the Philippines are necessary to make more definite conclusions. We have already started a study to provide education for parents and teachers. It is important to be aware of the types of risk factors related to child-raising anxieties in parents and to provide education for parents.

\section{Conclusions}

In conclusion, there were some differences in the cognition of child-raising anxiety between the parents and the teacher. The percentages of children regarding whom the parents felt anxiety tended to be higher than the corresponding percentages for the teacher, and there were some differences in the details of the child-raising anxieties between the parents and the teacher. The Kaup 
index, whether or not the child was the first child, and the place of delivery might affect the cognition of parents regarding whether they felt their child was difficult to raise. These findings suggest that the provision of health checkups and information on child-raising anxiety and difficult-to-raise preschool children is an important way of improving the detection of health problems and health promotion among children, parents and teachers in deprived areas of the Philippines.

It was a limitation of this study that it was conducted in a single facility in the Philippines. Of course, the data cannot be generalized to all facilities in the country. Future studies should assist in the education system, such as providing lectures and information using Facebook, which is a common social networking tool in the Philippines, not only regarding difficult-to-raise preschool children but also physically handicapped children. The increase in the range of applications for the education system would encourage the growth of knowledge of the parents and teachers regarding difficult-to-raise children.

\section{Acknowledgments}

This research was supported in part by Grants-in-aid for Scientific Research No. 17K01899 from the Japan Society for the Promotion of Science. The authors wish to acknowledge the support of all the staff of the AKCDF and all the Japanese medical volunteers.

\section{REFERENCES}

[1] Fuji T, Kobayashi M. Association of children with special care needs and developmental disorders, Toyama Development Welfare Studies, Vol.1, 41-48.

[2] World Health Organization, World Health Statistics 2015, Online available fromhttp://www.who.int/gho/publications/world_health_st atistics/2015/en/

[3] National Statistics Office of Philippines, Philippines National Demographic and Health Survey 2008, Online available

fromhttp://dhsprogram.com/pubs/pdf/FR224/FR22

[4] Republic of the Philippines Department of Health, Child Health and strategic plan, Online available from http://www.doh.gov.ph/node/342.html

[5] Yamamoto Y, Matsuo H, Mori K. Continuous Survey on Child Health Assessed by Medical Checkups in Deprived Areas of the Philippines, Universal Journal of Public Health, Vol.2, No.8, 230-235.

[6] Ministry of Health, Labour and Welfare of Japan, Preventing the outbreak of child abuse, Online available from http://www.mhlw.go.jp/bunya/kodomo/dv12/02.html

[7] Hongo K, Sawae Y, Suzuki T. Survey on specific action regarding difficult-to-raise children and correspondence of their parents, Japanese Journal on Developmental Disabilities, Vol.25, No.1, 50-61.

[8] Tamura M, Hashimoto S, Akiyama T. Developing a checklist to support parents feeling difficult, Japanese Journal on Support System for Developmental Disabilities, Vol.6, No.1, 9-13.

[9] Japan International Cooperation Agency, Mother and Child Book of the Philippines, Online available from http://www.jica.go.jp/project/philippines/0600894/04/ 